\section{Probing the Mechanisms of the Yellow Vine Syndrome Development in the American Cranberry: Shade Effect}

\author{
Zi Wei \\ Department of Chemistry and Biochemistry, University of Massachusetts \\ Dartmouth, 285 Old Westport Road, North Dartmouth, MA 02747 \\ Peter Jeranyama \\ University of Massachusetts Amherst, Cranberry Experiment Station, 1 State \\ Bog Road, East Wareham, MA 02538
}

Fan Zhang

Department of Chemistry and Biochemistry, University of Massachusetts Dartmouth, 285 Old Westport Road, North Dartmouth, MA 02747

Carolyn DeMoranville

University of Massachusetts Amherst, Cranberry Experiment Station, 1 State Bog Road, East Wareham, MA 02538

Harvey J.M. Hou ${ }^{1}$

Department of Chemistry and Biochemistry, University of Massachusetts Dartmouth, 285 Old Westport Road, North Dartmouth, MA 02747

Additional index words. yellow vine syndrome, cranberry, spectrometry, HPLC, chlorophyll fluorescence analysis, shade

\begin{abstract}
Yellow vine symptoms are often observed in cranberry bogs. To explore the mechanisms of the formation of yellow vine syndrome in cranberry leaves, the shade effect on the chlorophyll ( $\mathrm{Chl}$ ) content and photosynthetic activities in cranberry bogs were investigated by spectrometric, high-performance liquid chromatography (HPLC), and in vivo $\mathrm{Chl}$ fluorescence kinetics. Spectrometric and HPLC analyses revealed that the yellow vine leaves were associated with a $11 \% \pm 5 \%$ and $14 \% \pm 5 \%$ increase in $\mathrm{Chl} a /$ $\mathrm{Chl} b$ ratio after shading, respectively. The $\mathrm{Chl} a / \mathrm{Chl} b$ ratio was the same in both types of leaves, suggesting the photosystem (PS) II organization remains invariant. The rise in chlorophyll content suggested that the number of reaction sites on PS II is increased in the shaded yellow vine leaves. The results of in vivo chlorophyll fluorescence analysis also indicated that the electron transport chain in the PS II is enhanced and that the size of the quinone pool is increased. In addition, the overall photosynthesis index is drastically improved by shading. These three lines of evidence imply that the shading of cranberry plants appeared to reduce the syndrome by improving the photosynthetic activity and increasing the chlorophyll content. The techniques presented here may be valuable for characterizing variations of plants by stress or disease.
\end{abstract}

The American cranberry (Vaccinium macrocapron Ait.) contains abundant antioxidants (Vinson et al., 2008) and is an important and nutritious food and beverage source. It also has noteworthy health benefit in fighting human cardiovascular and cancer diseases (Deyhim et al., 2007; Lipson et al., 2007; Neto, 2007; Neto et al., 2008). The production and quality of cranberries may be affected by long-term or short-term environmental stress such as water (De Moranville et al., 2009), nutrient (Torio

Received for publication 29 June 2010. Accepted for publication 14 July 2010.

This work was supported by grants from the USDA CSREES, the UMass Dartmouth Chancellor's Research Fund, and UMass Dartmouth Cranberry Research Program.

${ }^{1}$ To whom reprint requests should be addressed; e-mail hhou@umassd.edu.
The distinguishing characteristic of yellow vine-affected plants is that the phloem, which normally has a clear translucent appearance, becomes honey-colored, particularly in the crown area. The yellow vine phenotype cranberry cultivar, Stevens, is widely planted in Massachusetts. The yellow vine syndrome might affect the production and quality of cranberry in Massachusetts.

Although foliar symptoms of yellow vine are similar to vine decline symptoms caused by soilborne pathogens, root degeneration occurs only in the later stages of yellow vine development. It has been reported that plant nutrition may be related to the yellow vine syndrome in cranberry leaves in Massachusetts (Demoranville, 2006). Additionally, the yellow vine syndrome often worsens in bogs with drainage problems, indicating that water stress may be another factor in the formation of yellow vine in cranberries (Demoranville, 2006). Whether the yellow vine symptom affects the production and quality of cranberry is still not clear. The mechanism for developing the yellow vine syndrome in cranberry is poorly understood and needs to be elucidated.

One important feature of the yellow vine cranberry leaves is the color change from green to yellow, which is probably the result of the decrease of chlorophyll (Chl) content. As is well known, chlorophyll is a part of the photosynthetic reaction centers in green plants that function as light-harvesting antenna. The decrease of Chl may be a signal of photodamage of the photosystem (PS) II in leaves as a result of excessive exposure to light. To probe the mechanisms of the formation of yellow vine syndrome in cranberry leaves, the shade effect on the Chl content and photosynthetic activity in cranberry were investigated by spectrometric, high-performance liquid chromatography (HPLC), and in vivo Chl fluorescence kinetics.

\section{Materials and Methods}

Cranberry sample treatment. Leaves of cranberry cultivar Stevens growing in 1) shaded areas and 2) outside shaded areas were collected from State Bog in East Wareham, MA. Four sets of shade structures were placed in the bog. Three sets of samples were harvested under each site and quantified immediately or stored at $-80^{\circ} \mathrm{C}$ for later use. To extract the pigments from the cranberry leaves, $\approx 5 \mathrm{~g}$ of leaves was shredded completely at $4{ }^{\circ} \mathrm{C}$ in a blender. The resulting leave paste mixtures were extracted by $50 \mathrm{~mL}$ of methanol (analytical grade, purchased from Sigma, St. Louis, MO) for $1 \mathrm{~h}$. The methanol extract solution was immediately analyzed by spectrometric and HPLC methods or stored in the dark at $-80^{\circ} \mathrm{C}$ for later use.

Chlorophyll determination by ultravioletvisible absorption spectrometry. The methanol extract of cranberry leaves was diluted with methanol to proper concentration before spectrometric measurement. Typically, 100- $\mu \mathrm{L}$ extractions were diluted 1000 times with the extract solvent. The ultraviolet-visible 
absorption spectra were recorded with Hewlett Packard 8452A diode array spectrophotometer (Agilent Inc., Santa Clara, CA) with a 1-cm light path cuvette. The concentration of Chl $a$ and Chl $b$ was calculated according to the published procedures (Porra et al., 1989).

High-performance liquid chromatography analysis of chlorophyll contents in cranberry leaves. A reverse-phase HPLC column $(2500 \times$ $4.6 \mathrm{~mm}$, Grace Prevail C18 $5 \mathrm{u}$; Fisher Scientific, Waltham, MA) with a diode array detector (DAD) (HP 1200 series LC systems; Agilent Inc., Santa Clara, CA) was used for HPLC analysis according to the procedures published (De las Rivas et al., 1989). The column was equilibrated with acetonitrile: methanol ( $7: 1$ by $\mathrm{v} / \mathrm{v}$, mobile phase A). After the sample was injected, the mobile phase A was pumped at the flow rate of $1 \mathrm{~mL} \cdot \mathrm{min}^{-1}$ for $2 \mathrm{~min}$. A mixture of acetonitrile:methanol:water:ethyl acetate (7:0.96:0.04:2, mobile phase B) was then pumped for $1 \mathrm{~min}$. Finally, acetonitrile:methanol:water:ethyl acetate (7:0.96:0.04:8, mobile phase C) was pumped until all the components were eluted. The detection wavelength was $450 \mathrm{~nm}$. The standard solution of Chl $a(1.00 \mathrm{ppm}$ in methanol) was prepared using Chl $a$ purchased from Sigma and used for HPLC analysis. The quantitative analysis of Chl $b$ was conducted using the response factor of Chl $a$. The chromatographic peaks were identified by four different ways: the internal standard, absorption spectra obtained by a DAD, liquid chromatography-mass spectroscopy, and published HPLC data (De las Rivas et al., 1989).

In vivo chlorophyll fuorescence analysis of cranberry leaves in bog. The Chl fluorescence parameters of cranberry leaves in bogs were determined with Pocket PEA Chlorophyll Fluorimeters (Hansatech Instruments Ltd., Norfolk, U.K.). Shaded and unshaded yellow vine leaves were collected randomly and used for Chl fluorescence measurements immediately. The in vivo $\mathrm{Chl}$ fluorescence parameters were determined after a 10-min dark period in the bog. The measurements were collected using attached leaves. The comparison of detached and attached leaves was conducted with agreeable parameters with the considerable relative error of $10 \%$ to $15 \%$. The field experiments were carried out once a week for 4 weeks in Oct. 2008. To obtain the reliable Chl fluorescence data, an average of five individual repeated measurements were used to calculate the photosynthetic parameters.

\section{Results and Discussion}

Chlorophyll content by spectrometric and high-performance liquid chromatography analysis. The yellow vine syndrome on cranberry leaves appears as yellowing along leaf margins. The Chl content is expected to be lower than the normal cranberry leaves. The shading of the yellow vine plants seemed to passively affect $\mathrm{Chl}$ concentrations and may not have any effect on nutrient concentrations (Sicuranza et al., 2009). The Chl contents of the yellow vine samples in the absence and presence of shade were determined by spectrometric analysis (Table 1). Shading increased Chl $a$ and Chl $b$ content by $11.1 \%$ and $13.9 \%$, respectively. At the $90 \%$ confidence level, both the changes of $\mathrm{Chl} a$ and $\mathrm{Chl} b$ in concentration after shading are considered to be significant statistically. HPLC analysis of shaded and unshaded yellow vine leaves using a C18 column with a photodiode array detector following the published procedures was conducted and confirmed the spectrometric data.

This observation may be explained by the increase in the rate of $\mathrm{Chl}$ biosynthesis in yellow vine cranberry leaves. For example, the shading may activate the photoreceptor and turn on the genes involved in the Chl biosynthesis pathway (Ito et al., 2008; Masuda, 2008; Tanaka and Tanaka, 2007). Alternatively, the partial recovering of Chl may be the result of the slow photodegradation and photodamage of Chls. It has been demonstrated that $\mathrm{Chl}$ is photosensitive to the damage from the excess light and degraded rapidly (Hou et al., 1996; Melis, 1999; Nedbal et al., 1992; Telfer and Barber, 1989; Tracewell et al., 2001). The photodamage and photodegradation of Chl is associated with highly active singlet oxygen species formed by triplet Chls (Hou et al., 1998; Telfer et al., 1994; Tracewell et al., 2001).

Table 1 also showed that the $\mathrm{Chl} a / \mathrm{Chl} b$ ratio in the unshaded yellow vine samples was 1.36 , whereas the $\mathrm{Chl} a / \mathrm{Chl} b$ ratio was 1.34 in the shaded leaves. The photosynthetic reaction centers of PS I and PS II in higher plants contain the Chl $a$ without $\mathrm{Chl} b$. In contrast, the light-harvesting system contains both Chl $a$ and Chl $b$. The comparable Chl $a / \mathrm{Chl} b$ ratio in both samples suggested that the ratio of the reaction center to the lightharvesting system in cranberry leaves is unchanged. We proposed that the organization of photosynthetic machinery in yellow vine cranberry plants may not be affected by the shading. The increase in Chl content would imply the increase in the number of reaction centers in both PS II and the light-harvesting complex.

Chlorophyll fluorescence analysis. The Chl fluorescence is a unique tool to study photosynthetic reaction in cyanobacteria, algae, and higher plants in vivo and is widely used to monitor plant response to the environmental stress, including photoinhibition, chilling, salinity, and water (Adams and DemmigAdams, 2004; Baker, 2008; Pospisil and Dau, 2000; Vredenberg, 2008). The typical Chl fluorescence transients, O-J-I-P curves (Strasser et al., 2004), exhibited on illumination of a dark-adapted cranberry sample in the absence and presence of shade by saturating light, are shown in Figure 1. The transient revealed three steps: 1 ) $\mathrm{O} \rightarrow \mathrm{J}$ (on the $10 \mu$ s to $1-\mathrm{ms}$ scale) is associated with the electron transfer from $\mathrm{P}_{680} *$ to $\mathrm{Q}_{\mathrm{A}}$ and Mn-cluster to $\mathrm{P}_{680}{ }^{+}$; 2) $\mathrm{J} \rightarrow \mathrm{I}$ (on the $1 \mathrm{~ms}$ to $100 \mathrm{~ms}$ ) is related to the electron transfer from $\mathrm{Q}_{\mathrm{A}}$ to $\mathrm{Q}_{\mathrm{B}}$; and 3$) \mathrm{I} \rightarrow \mathrm{P}(100 \mathrm{~ms}$ to $1 \mathrm{~s})$ is the result of the

Table 1. Spectrometric analytical results of chlorophyll (Chl) $a$, Chl $b$, and the $\mathrm{Chl} a / \mathrm{Chl} b$ ratio in the methanol extracts of yellow vine samples in the absence and presence of shade. ${ }^{\mathrm{z}}$

\begin{tabular}{lccc}
\hline & Unshaded yellow vine leaves & Shaded yellow vine leaves & Change $(\%)$ \\
\hline Chl a $\left(\mathrm{mg} \cdot \mathrm{g}^{-1}\right)$ & $0.99 \pm 0.05$ & $1.10 \pm 0.06$ & +11.1 \\
$\mathrm{Chl} \mathrm{b}\left(\mathrm{mg} \cdot \mathrm{g}^{-1}\right)$ & $0.72 \pm 0.04$ & $0.82 \pm 0.04$ & +13.9 \\
$\mathrm{Chl} a / \mathrm{Chl} b$ & $1.37 \pm 0.06$ & $1.34 \pm 0.06$ & -0.02 \\
\hline
\end{tabular}

${ }^{\mathrm{z}}$ The average of three measurements was used to calculate the SDS.

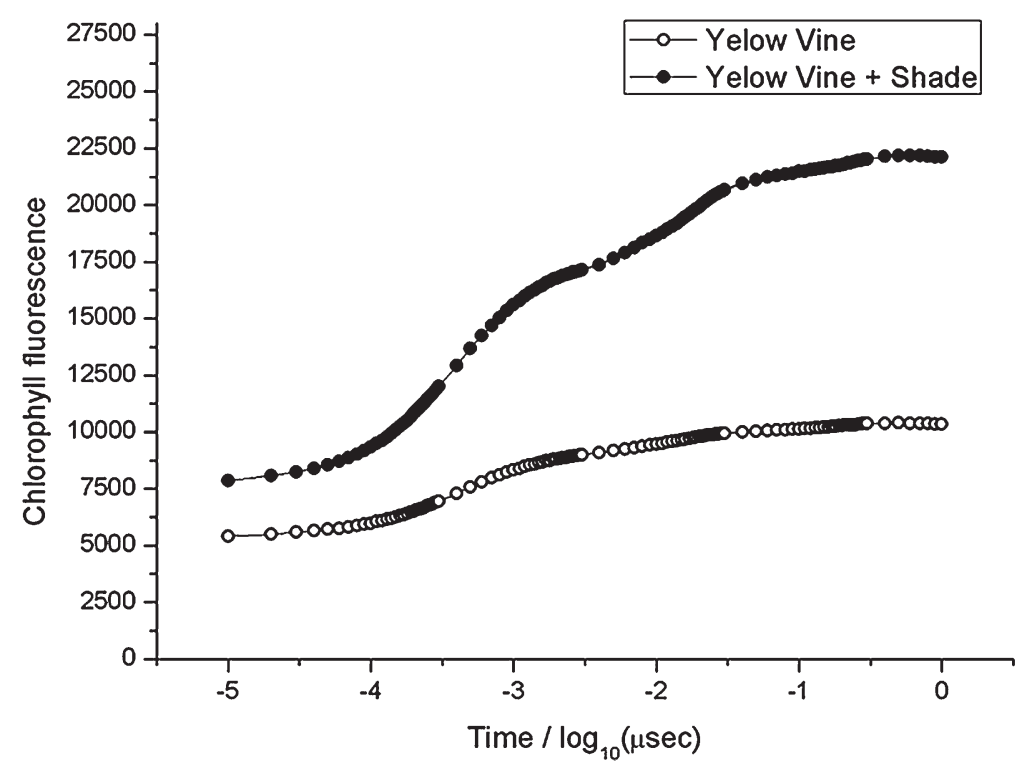

Fig. 1. Chlorophyll fluorescence transients of the yellow vine cranberry samples in the absence (open symbols) and presence (filled symbols) of shade. Each single curve represents the average of five independent chlorophyll fluorescence measurements. 
double reduction of $\mathrm{Q}_{\mathrm{B}}$ and the electron transfer from $\mathrm{Q}_{\mathrm{B}}$ to $\mathrm{PS}$ I.

Figure 1 showed that shading increased the fluorescence levels significantly on the three steps $(\mathrm{O} \rightarrow \mathrm{P}, \mathrm{P} \rightarrow \mathrm{I}$, and $\mathrm{I} \rightarrow \mathrm{J})$, indicating the shade may improve the photosynthetic efficiency. The derivation of formulas for the interpretation of data in O-J-I-P transient to structural and functional parameter quantifying PS II behavior includes initial fluorescence $\left(\mathrm{F}_{\mathrm{o}}\right)$, variable fluorescence $\left(\mathrm{F}_{\mathrm{v}}\right)$, maximum fluorescence $\left(\mathrm{F}_{\mathrm{m}}\right)$, total lifetime constant, which is the time to reach the maximum fluorescence), and PS II maximum quantum yield $\left(\mathrm{F}_{\mathrm{v}} / \mathrm{F}_{\mathrm{m}}\right)$ (Strasser et al., 2004). The size of the PS II quinone pool may be expressed as "area," which is the measurement of fluorescence area above the transient (Strasser et al., 2004). The photosynthesis index is defined as a driving force of the primary photosynthetic reaction (Srivastava et al., 1999). The spider plots of Chl fluorescence data provide an overall picture of photosynthetic efficiency in plants in vivo (Strasser et al., 2004). A spider plot of Chl fluorescence for cranberry samples revealed that five of the six parameters of shaded yellow vine leaves were increased dramatically than those of unshaded samples (Fig. 2). The dark line stands for the parameters for the unshaded yellow vine samples. The discontinuous line represents the measurements of yellow vine under shade. The total lifetime constant is almost unchanged,

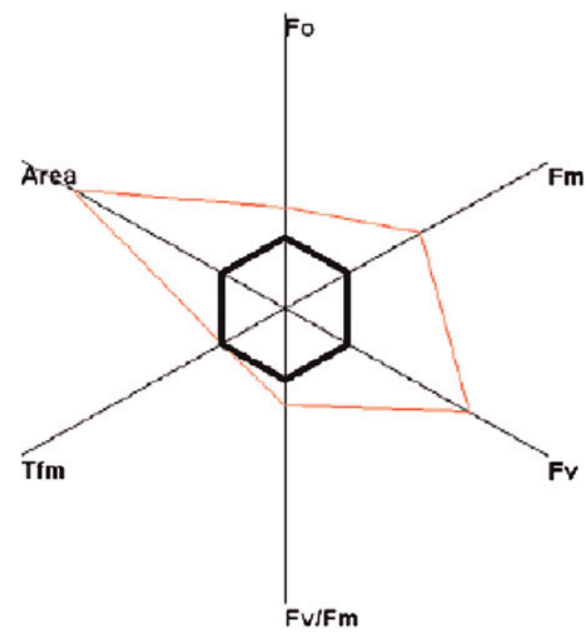

Fig. 2. A spider plot of the chlorophyll fluorescence parameters for yellow vine cranberry leaves in the absence (black line) and presence (red line) of shade. Each experimental point represents the average of five chlorophyll fluorescence measurements with relative SE of $\approx 20 \%$. suggesting the electron transfer kinetic in PS II remains the same. This observation agrees with the notion that PS II organization is unaffected by the shade. The yellow vine leaves increased their $\mathrm{F}_{\mathrm{o}}$ and this may be the result of the partial dissociation of Chl in PS II. In the spider plot, the $F_{v}$ and $F_{m}$ was increased by a factor of 2 to 3 under shade. Overall, the $\mathrm{F}_{\mathrm{v}} / \mathrm{F}_{\mathrm{m}}$ ratio was increased by $\approx 20 \%$. The rise in $\mathrm{F}_{\mathrm{v}} / \mathrm{F}_{\mathrm{m}}$ indicated the enhancement of PS II electron transfer activity, which supports our hypothesis that the number of PS II is increased based on Chl analysis. Similar behavior was observed in camellia leaves with development of an energy pipeline model of the photosynthetic apparatus (Kruger et al., 1997; Strasser, 1987). In addition, the "area" above the fluorescence transient for the shaded sample is also increased drastically, indicating the presence of a larger quinone pool (Toth et al., 2007).

We noticed that shading on the yellow vine leaves showed a considerable positive effect on improving PS II efficiency as in Figure 2. For example, the $\mathrm{F}_{\mathrm{m}}, \mathrm{F}_{\mathrm{v}}$, and "area" were increased by a factor of greater than 2 . This is somewhat inconsistent with the $\mathrm{Chl}$ data $(\approx 10 \%$ to $15 \%$ increase) by spectrometric and HPLC analysis. We conducted a monthly Chl fluorescence experiment to clarify the discrepancy between the Chl fluorescence assay and Chl determination by the spectrometric and HPLC method. The three Chl fluorescence parameters, including $\mathrm{F}_{\mathrm{v}} /$ $F_{m}$, "area," and photosynthesis index factor, were averaged over the 4 weeks and listed in Table 2. We found 1) the Chl fluorescence parameters of unshaded yellow vine samples varied with the time appreciably (see the measured error in Table 2). Yellow vine leaves may be more sensitive to the environmental stress. This may be the result of the variation of several factors such as temperature, weather, water, and use of herbicides in bogs over a month. The other possible reason could be variation resulting from sampling; and 2) shaded yellow vine sample showed a relative steady and constant value over time. The SDs of shaded yellow vine syndrome leaves were decreased by a factor of 2 to 10 (Table 2). This may indicate the partial recovery of yellow vine syndrome under shade and enhanced the capability to respond the stress conditions.

To further examine the effect of shade on yellow vine cranberry leaves, a complete data set on the non-yellow vine controls (healthy green cranberry) was collected. These measurements were conducted under the identical shading experiments following the same

Table 2. Photosynthetic parameters of the shaded and unshaded cranberry leaves determined by the chlorophyll fluorescence kinetics. ${ }^{\mathrm{z}}$

\begin{tabular}{lcrr}
\hline Sample conditions & $\mathrm{F}_{\mathrm{v}} / \mathrm{F}_{\mathrm{m}}$ & Area $\left(\times 10^{5}\right.$ unit) & PI \\
\hline Unshaded yellow vine leaves & $0.72 \pm 0.10$ & $1.9 \pm 0.9$ & $0.32 \pm 0.20$ \\
Shaded yellow vine leaves & $0.85 \pm 0.01$ & $2.1 \pm 0.4$ & $0.35 \pm 0.06$ \\
\hline zThe "area," is a measurement of the size of photosystem & II quinone pool with arbitrary unit and is \\
fluorescence area above the transient (Strasser et al., 2004). The photosynthesis index (PI) is defined \\
a driving force of the primary photosynthetic reaction (Srivastava et al., 1999). \\
$\mathrm{F}_{\mathrm{v}} / \mathrm{F}_{\mathrm{m}}=$ variable fluorescence/maximum fluorescence.
\end{tabular}

procedures. The data gave a similar increase of $10 \%$ to $15 \%$ in $\mathrm{Chl}, \mathrm{F}_{\mathrm{v}} / \mathrm{F}_{\mathrm{m}}$, "area," and photosynthesis index factor. In addition, the $\mathrm{Chl} a / \mathrm{Chl} b$ ratio was unaffected by shading. This phenomenon suggests that the increase of Chl by shading is not specific to yellow vine disease and may be general to plant leaves. We cannot exclude the contribution of yellow vine syndrome and other shading effects. It also suggested that photodamage of photosynthetic systems occurs under normal sunlight condition. The sunlight intensity in the cranberry bog is likely too much for photosynthesis in cranberry plants and high enough to cause perceptible photodamage.

\section{Conclusions}

Spectrometric and HPLC analysis revealed that the leaves of yellow vine cranberry under shade increase their content of chlorophylls by $11 \%$ to $14 \%$ than the ones unshaded. However, the $\mathrm{Chl} a / \mathrm{Chl} b$ ratio was unaffected by the shade. The Chl fluorescence kinetics indicated that the PS II quantum efficiency, quionone pool, and overall photosynthesis performance enhanced by $10 \%$ to $15 \%$. The shade effect on normal cranberry leave generates similar improvement in these parameters. Our results suggest that the shade effect will increase the number of PS II, including reaction center and lightharvesting complex in cells of the yellow vine cranberry leaves. Because the PS II is the main target of photoinhibition, we speculate a possible role of photoinhibition associated with the yellow vine syndrome in cranberry plants. However, we cannot rule out the involvement of other outcomes of shading. We believe that the approach presented in this work may be useful for characterizing variations of plants that have been affected by stress or disease.

\section{Literature Cited}

Adams W.W., III and B. Demmig-Adams. 2004. Chlorophyll fluorescence as a tool to monitor plant response to the environment, p. 583-604. In: Papageorgiou, G.C. and Govindjee (eds.). Chlorophyll a fluorescence: A signature of photosynthesis. Springer, Dordrecht, The Netherlands.

Allan, D.L., B.D. Cook, and C.J. Rosen. 1994. Nitrogen form and solution $\mathrm{pH}$ effect on organic acid content of cranberry roots and shoots. HortScience 29:313-315.

Baker, N.R. 2008. Chlorophyll fluorescence: A probe of photosynthesis in vivo. Annu. Rev. Plant Biol. 59:89-113.

Blodgett, A.B., R.W. Caldwell, and P.S. McManus. 2002. Effects of calcium salts on the cranberry fruit rot disease complex. Plant Dis. 86:747752 .

Davenport, J.R., J. Hart, K. Patten, T.R. Roper, C.J. DeMoranville, S. Kumidini, and A. Poole. 2003. Spatial and temporal variability of cranberry soil pH. Acta Hort. 626:315-327.

De las Rivas, J., A. Abadia, and J. Abadia. 1989. A new reversed-phase HPLC method resolving all major higher plant photosynthetic pigments. Plant Physiol. 91:190-192. 
Demoranville, C. 2006. Cranberry best management practice adoption and conservation farm planning in Massachusetts. HortTechnology 16: 393-397.

DeMoranville, C., B. Howes, D. Schlezinger, and D. White. 2009. Cranberry phosphorus management: How changes in practice can reduce output in drainage water. Acta Hort. 810:633640 .

Demoranville, I.E. and R.M. Devlin. 1976. The effects of two growth regulator herbicides on cranberry plant development. Proc. Annu. Mtg Northeastern Weed Sci. Soc. 30:152-155.

Deyhim, F., B.S. Patil, A. Villarreal, E. Lopez, K. Garcia, R. Rios, C. Garcia, C. Gonzales, and K. Mandadi. 2007. Cranberry juice increases antioxidant status without affecting cholesterol homeostasis in orchidectomized rats. J. Med. Food 10:49-53.

Finn, C.E., C.J. Rosen, and J.J. Luby. 1990. Nitrogen form and solution $\mathrm{pH}$ effects on root anatomy of cranberry. HortScience 25:1419-1421.

Forney, C.F., W. Kalt, S.R. Abrams, and S.J. Owen. 2009. Effects of postharvest light and ABA treatments on the composition of lateharvested white cranberry fruit. Acta Hort. 810: 799-806.

Forsyth, F.R. and I.V. Hall. 1967. Rates of photosynthesis and respiration in leaves of the cranberry with emphasis on rates at low temperatures. Can. J. Plant Sci. 47:19-23.

Hou, J.M., T.Y. Kuang, D.C. Peng, C.Q. Tang, and P.S. Tang. 1996. The photodamage and protective role of pheophytin a in the photosystem II reaction center against light-induced damage. Prog. Nat. Sci. 6:489-493.

Hou, J.M., T.Y. Kuang, D.C. Peng, C.Q. Tang, and P.S. Tang. 1998. Photoinduced damage of the photosystem II primary electron donor $\mathrm{P}_{680}$, p. 2119-2122. In: Garab, G. (ed.). Photosynthesis: Mechanisms and effects. Vol. 3. Springer, Dordrecht, The Netherlands.

Ito, H., M. Yokono, R. Tanaka, and A. Tanaka. 2008. Identification of a novel vinyl reductase gene essential for the biosynthesis of monovinyl chlorophyll in Synechocystis sp. PCC6803. J. Biol. Chem. 283:9002-9011.

Kruger, G.H.J., M. Tsimilli-Michael, and R.J. Strasser. 1997. Light stress provokes plastic and elastic modifications in structure and func- tion of photosystem II in camellia leaves. Physiol. Plant 101:265-277.

Lipson, S.M., P. Cohen, J. Zhou, A. Burdowski, and G. Stotzky. 2007. Cranberry cocktail juice, cranberry concentrates, and proanthocyanidins reduce reovirus infectivity titers in African green monkey kidney epithelial cell cultures. Mol. Nutr. Food Res. 51:752-758.

Masuda, T. 2008. Recent overview of the $\mathrm{Mg}$ branch of the tetrapyrrole biosynthesis leading to chlorophylls. Photosynth. Res. 96:121-143.

Melis, A. 1999. Photosystem-II damage and repair cycle in chloroplasts: What modulates the rate of photodamage in vivo? Trends Plant Sci. 4: 130-135.

Nedbal, L., G. Samson, and J. Whitmarsh. 1992. Redox state of a one-electron component controls the rate of photoinhibition of photosystem II. Proc. Natl. Acad. Sci. USA 89:7929-7933.

Neto, C.C. 2007. Cranberry and its phytochemicals: A review of in vitro anticancer studies. J. Nutr. 137:186S-193S.

Neto, C.C., J.W. Amoroso, and A.M. Liberty. 2008. Anticancer activities of cranberry phytochemicals: An update. Mol. Nutr. Food Res. 52(suppl 1):S18-S27.

Porra, R.J., W.A. Thompson, and P.E. Kriedemann. 1989. Determination of accurate extinction coefficients and simultaneous equations for assaying chlorophylls a and b extracted with four different solvents: Verification of the concentration of chlorophyll standards by atomic absorption spectroscopy. Biochim. Biophys. Acta 975:384-394.

Pospisil, P. and H. Dau. 2000. Chlorophyll fluorescence transients of photosystem II membrane particles as a tool for studying photosynthetic oxygen evolution. Photosynth. Res. 65:41-52.

Sandler, H.A. and C.J. DeMoranville. 1999. Influence of cranberry soil surface characteristics on the activity of dichlobenil. HortScience 34:1048-1050.

Sicuranza, J., P. Jeranyama, H.J.M. Hou, and C. DeMoranville. 2009. Shade effects on chlorophyll content and nutrient content of cranberry vines exhibiting yellow vine symptoms. HortScience 44:553 (abstr.).

Srivastava, A., R.J. Strasser, and Govindjee. 1999. Greening of peas: Parallel measurements of 77 $\mathrm{K}$ emission spectra, OJIP chlorophyll a fluores- cence transient, period four oscillation of the initial fluorescence level, delayed light emission, and $\mathrm{P}_{700}$. Photosynthetica 37:365-392.

Strasser, R.J. 1987. Energy pipeline model of the photosynthetic apparatus, p. 717-720. Vol. 2. In: Biggins, J. (ed.). Progress in photosynthesis research. Springer, Dordrecht, The Netherlands.

Strasser, R.J., M. Tsimilli-Michael, and A. Srivastava. 2004. Analysis of the chlorophyll a fluorescence transient, p. 321-362. In: Papageorgiou, G.C. and Govindjee (eds.). Chlorophyll a fluorescence: A signature of photosynthesis. Springer, Dordrecht, The Netherlands.

Tanaka, R. and A. Tanaka. 2007. Tetrapyrrole biosynthesis in higher plants. Annu. Rev. Plant Biol. 58:321-346.

Telfer, A. and J. Barber. 1989. Evidence for the photoinduced oxidation of the primary electron donor $\mathrm{P}_{680}$ in the isolated photosystem II reaction center. FEBS Lett. 246:223-228.

Telfer, A., S.M. Bishop, D. Phillips, and J. Barber. 1994. Isolated photosynthetic reaction center of photosystem II as a sensitizer for the formation of singlet oxygen. Detection and quantum yield determination using a chemical trapping technique. J. Biol. Chem. 269:13244-13253.

Torio, J.C. and P. Eck. 1969. Nitrogen, phosphorus, potassium, and sulfur nutrition of the cranberry in sand culture. Proc. Am. Soc. Hort. Sci. 94: 622-625.

Toth, S.Z., G. Schansker, and R.J. Strasser. 2007. A noninvasive assay of the plastoquinone pool redox state based on the OJIP transient. Photosynth. Res. 93:193-203.

Tracewell, C.A., A. Cua, D.H. Stewart, D.F. Bocian, and G.W. Brudvig. 2001. Characterization of carotenoid and chlorophyll photooxidation in photosystem II. Biochemistry 40: 193-203.

Vinson, J.A., P. Bose, J. Proch, H. Al Kharrat, and N. Samman. 2008. Cranberries and cranberry products: Powerful in vitro, ex vivo, and in vivo sources of antioxidants. J. Agr. Food Chem. 56: 5884-5891.

Vredenberg, W.J. 2008. Analysis of initial chlorophyll fluorescence induction kinetics in chloroplasts in terms of rate constants of donor side quenching release and electron trapping in photosystem II. Photosynth. Res. 96:83-97. 